\title{
REVIEW
}

\section{Obesity in the critically ill: a narrative review}

\author{
Miet Schetz ${ }^{1 *}$ (D) Audrey De Jong ${ }^{2}$, Adam M. Deane ${ }^{3,4}$, Wilfried Druml ${ }^{5}$, Pleun Hemelaar ${ }^{6}$, Paolo Pelosi ${ }^{7,8}$, \\ Peter Pickkers ${ }^{6,9}$, Annika Reintam-Blaser ${ }^{10,11}$, Jason Roberts ${ }^{12,13,14,15}$, Yasser Sakr ${ }^{16}$ and Samir Jaber ${ }^{2}$
}

(C) 2019 Springer-Verlag GmbH Germany, part of Springer Nature

\begin{abstract}
The World Health Organization defines overweight and obesity as the condition where excess or abnormal fat accumulation increases risks to health. The prevalence of obesity is increasing worldwide and is around $20 \%$ in ICU patients. Adipose tissue is highly metabolically active, and especially visceral adipose tissue has a deleterious adipocyte secretory profile resulting in insulin resistance and a chronic low-grade inflammatory and procoagulant state. Obesity is strongly linked with chronic diseases such as type 2 diabetes, hypertension, cardiovascular diseases, dyslipidemia, non-alcoholic fatty liver disease, chronic kidney disease, obstructive sleep apnea and hypoventilation syndrome, mood disorders and physical disabilities. In hospitalized and ICU patients and in patients with chronic illnesses, a J-shaped relationship between BMI and mortality has been demonstrated, with overweight and moderate obesity being protective compared with a normal BMI or more severe obesity (the still debated and incompletely understood "obesity paradox"). Despite this protective effect regarding mortality, in the setting of critical illness morbidity is adversely affected with increased risk of respiratory and cardiovascular complications, requiring adapted management. Obesity is associated with increased risk of AKI and infection, may require adapted drug dosing and nutrition and is associated with diagnostic and logistic challenges. In addition, negative attitudes toward obese patients (the social stigma of obesity) affect both health care workers and patients.
\end{abstract}

Keywords: Obesity, Critically ill, Mortality paradox, Complications

\section{Introduction}

According to the World Health Organization (WHO), overweight and obesity are defined as the condition where excess or abnormal fat accumulation increases risks to health. Depending on the degree, duration and distribution of excess adipose tissue, these health risks are type 2 diabetes, hypertension, cardiovascular diseases, dyslipidemia, non-alcoholic fatty liver disease, chronic kidney disease, obstructive sleep apnea and hypoventilation syndrome, mood disorders and physical disabilities (Fig. 1). Some of these problems such as

\footnotetext{
*Correspondence: marie.schetz@uzleuven.be

${ }^{1}$ Division of Cellular and Molecular Medicine, Clinical Department and Laboratory of Intensive Care Medicine, KU Leuven University, Herestraat 49, 3000 Leuven, Belgium

Full author information is available at the end of the article
}

obstructive sleep apnea or physical disabilities are a direct consequence of the increased fat mass (obesity per se) but the majority results from the obesity-associated metabolic phenomena.

The amount of body fat is generally estimated with the body mass index (BMI) [weight $(\mathrm{kg}) /$ height $^{2}(\mathrm{~m})$ ], which forms the basis for the WHO classification (Table 1). BMI, however, becomes a poor marker of excess body fat in patients with either increased or low muscle mass (sarcopenic obesity) [1]. More important, patients with similar BMI may have different obesity-related complications depending on the distribution of excess fat (visceral and ectopic versus subcutaneous fat) [2,3]. Adipose tissue is highly metabolically active, and visceral adipose tissue has a more deleterious adipocyte secretory profile resulting in insulin resistance and a chronic low-grade inflammatory and procoagulant state. Subcutaneous fat in the lower body on the other hand may act as a metabolic sink for excess fat and protect other tissues/organs from

\section{亘 Springer}


lipotoxicity [2, 3]. Waist circumference (WC) and waisthip ratio (WHR) are tools to assess fat distribution and contribute to risk stratification [3] (Table 1).

Since 1975, the prevalence of obesity has tripled worldwide and is still increasing. It is currently one of the biggest health issues that affects all age groups, populations and countries of all income levels. This is also reflected in the intensive care unit (ICU) population where recent studies report a prevalence around 20\% $[4,5]$. Although the impact of obesity on ICU mortality is debated, it seems to be associated with morbidity [4] and increased resource utilization [6]. In this narrative review, based on exploratory literature searches, invited international experts summarize recent developments in the management of obese ICU patients. It aims to discuss the impact of obesity on different organ systems with the intention to assist ICU physicians in the management of this vulnerable population. A discussion of specific issues related to bariatric surgery is beyond the scope of this article.

\section{The obesity paradox}

Large cohort studies in the general population have demonstrated an increased mortality risk in both overweight

\section{Take-home message}

Obesity in the critically ill appears to be associated with lower mortality but increases the risk of complications in several organ systems.

and obese individuals [7]. However, more recent data in hospitalized patients or patients with chronic illnesses showed a J-shaped relationship between BMI and mortality, with overweight and moderate obesity being associated with lower mortality compared with a normal BMI or more severe obesity. The phenomenon that obesity increases the risk of obesity-related disease but paradoxically is associated with increased survival in patients with these diagnoses is called "obesity paradox." It has been observed in chronic diseases such as heart failure [8], coronary artery disease [9] and end-stage kidney disease [10], but also in acute conditions such as pneumonia [11], sepsis [12], acute respiratory distress syndrome (ARDS) [13] or critical illness in general $[4,14]$.

Whether the obesity survival paradox represents a real protective effect of adipose tissue has been challenged. First, admission of obese patients may be subjected

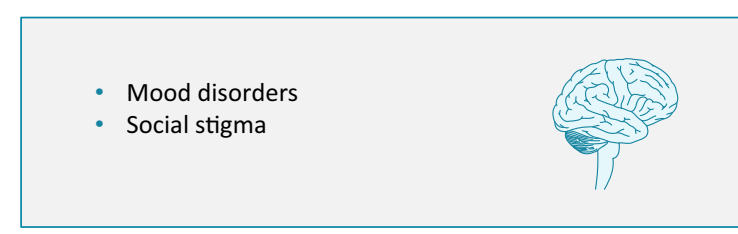

- Chronic inflammation

- Altered immunity

- Increased infection risk
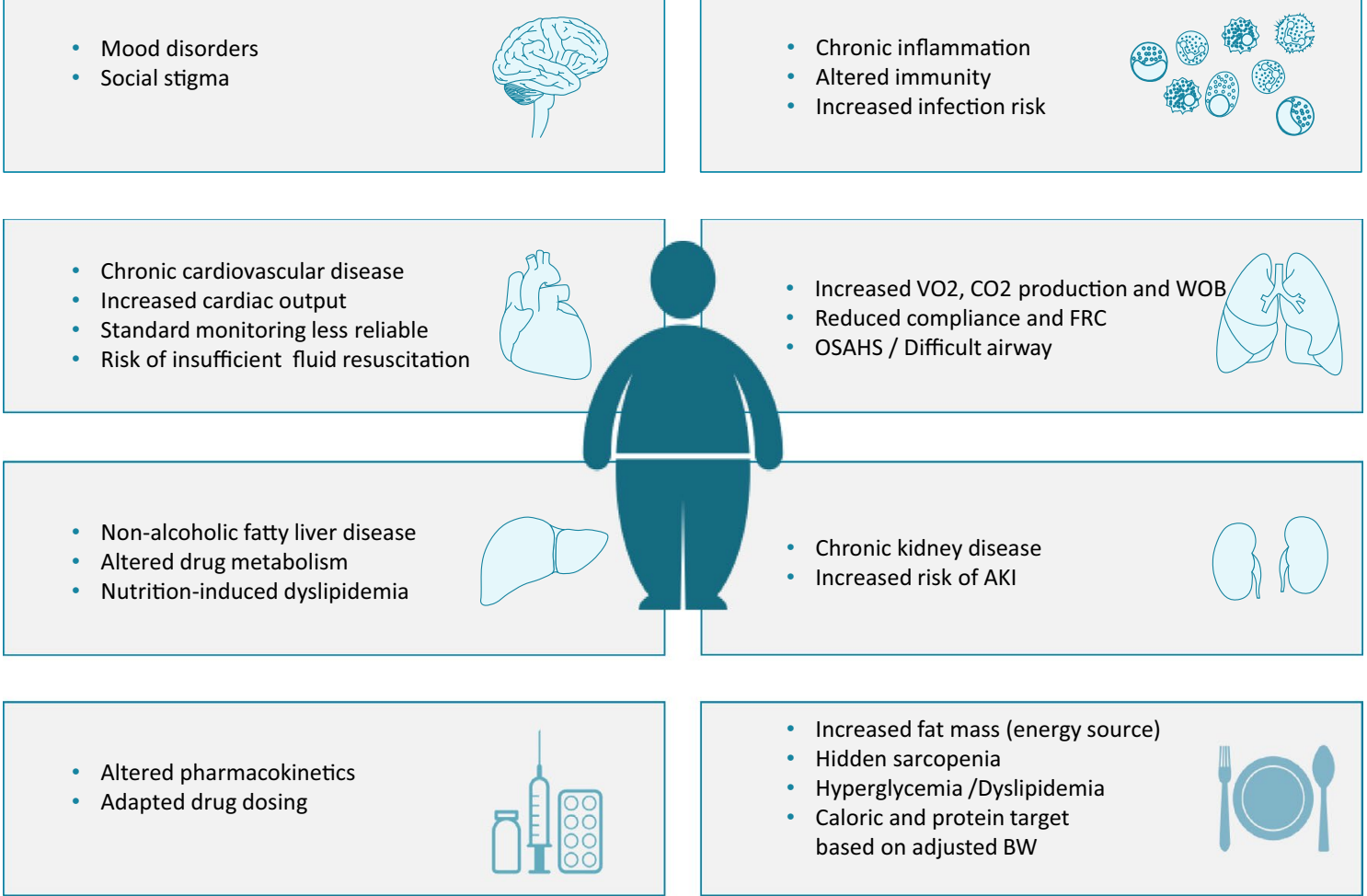

- Increased fat mass (energy source)

- Hidden sarcopenia

- Hyperglycemia /Dyslipidemia

- Caloric and protein target

based on adjusted BW

Fig. 1 Impact of obesity on organ systems and their management during critical illness. WOB work of breathing, FRC functional residual capacity, OSAHS obstructive sleep apnea and hypoventilation syndrome, BW body weight 
Table 1 WHO classification for obesity based on BMI

\begin{tabular}{|c|c|c|c|}
\hline Diagnosis & BMI $\left(\mathrm{kg} / \mathrm{m}^{2}\right)$ & $\begin{array}{l}\text { Disease risk } \\
\text { WC }(\mathrm{cm}) \text { males } \leq 94 \\
\text { Females } \leq 80\end{array}$ & $\begin{array}{l}\text { Disease risk } \\
\text { WC }(\mathrm{cm}) \text { males }>94 \\
\text { Females }>80\end{array}$ \\
\hline Underweight & $<18.5$ & & \\
\hline Normal weight & $18.5-24.9$ & & \\
\hline Overweight & $25-29.9$ & Increased & High \\
\hline Obesity class I (moderate obesity) & $30-34.9$ & High & Very high \\
\hline Obesity class II (severe obesity) & $35-39.9$ & Very high & Very high \\
\hline Obesity class III (very severe obesity) & $\geq 40$ & Extremely high & Extremely high \\
\hline
\end{tabular}

Within each BMI category, disease risk may vary depending on fat distribution reflected in waist circumference (WC)

to selection bias because of a lower threshold for ICU admission of otherwise young and healthy obese patients only for surveillance to avoid possible complications. Second, the obesity survival paradox has also been related to therapeutic factors. Obese patients frequently receive a lower weight-based dosage of fluids and vasopressors, potentially attenuating side effects of these therapies [15]. Third, the obesity paradox is typically reported in observational trials and meta-analyses that are subject to confounding and reverse causation [4, 14]. Finally, the use of BMI as a measure of obesity has been criticized. Indeed, in some obese individuals the high BMI may be related to an increased muscle mass or they may have a more advantageous (subcutaneous) fat distribution that is not associated with metabolic comorbidities, referred to as "metabolically healthy obesity." This condition has been linked to weaker adiposity-related inflammation and low risk of mortality. These phenotypes may confound the results of studies on the obesity paradox.

On the other hand, the hypothesis that "moderate obesity" in and by itself may be protective is increasingly adopted. Several mechanisms have been proposed. Being overweight or obese may be a marker of improved general health status (absence of illness-induced malnutrition) and better exposure to adequate health care. In addition, adipose tissue may also function as a fuel source and provide energy and lipid soluble nutrients during highly catabolic states [16]. A more likely explanation of the obesity survival paradox is that immunomodulatory substances secreted by fat cells (e.g., leptin, interleukin-10 and soluble TNF-alpha receptor) have immunomodulatory effects that might attenuate the inflammatory response and improve survival during severe illness [17, 18]. Most studies show higher leptin levels in ICU survivors [17]. Obese patients with acute lung injury have lower levels of proinflammatory cytokines (IL-6, IL-8) and surfactant protein D than non-obese patients [19]. Moreover, activated macrophages have been shown to infiltrate adipose tissue and switch from the proinflammatory M1 to the antiinflammatory M2 phenotype, with subsequent improvement in immune, antiinflammatory and scavenging functions in critical illness [16]. Higher lipoprotein and cholesterol levels may neutralize circulating endotoxin and provide precursors for adrenal steroid synthesis [20]. Future studies should focus on identifying the pathophysiologic mechanisms related to the obesity survival paradox and should consider the underlying disease conditions, therapeutic interventions and possible phenotypes.

\section{The respiratory system}

One of the main objectives of the critical care management of obese patients is prevention of respiratory complications. Respiratory management of obese ICU patients may differ between patients with healthy lungs and those with ARDS at ICU admission [21].

\section{Differences in respiratory system}

Oxygen consumption, production of carbon dioxide, work of breathing and abdominal pressure are increased in obese patients, whereas compliance of the respiratory system and functional residual capacity are decreased [22]. Obesity is a major risk factor of obstructive apnea syndrome. These factors in obese patients may partly explain the higher incidence of difficult airway management, atelectasis and respiratory complications [23]. However, perioperative mortality is not higher in obese compared with non-obese patients [24].

One of the most life-threatening respiratory complications is ARDS. Incidence of ARDS is higher in obese patients, as suggested in a meta-analysis performed in 30,583 patients [25] [pooled OR 1.89 (95\% CI 1.45-2.47)]. However, the prognosis of obese ARDS patients appears better compared with their non-obese counterparts ("obesity paradox") [26].

\section{Airway management}

Obesity is a risk factor for difficult intubation and difficult mask ventilation [27]. Elevated Mallampati score, limited mouth opening, reduced cervical mobility, presence of an obstructive apnea syndrome, coma and severe hypoxemia are associated with difficult intubation in 


\begin{abstract}
(See figure on next page.)
Fig. 2 Schematic presentation of the effects of regional transpulmonary pressures at different airway pressures on aeration (light blue area), atelectasis (dark blue area) and regional perfusion (red bands) in mechanically ventilated obese patients in supine position. PEEP positive end-expiratory pressure, Pplat plateau pressure of the respiratory system, $P p /$ pleural pressure, $P L$ transpulmonary pressure (distending pressure of the lung); a ventilation at low positive end-expiratory pressure (PEEP) levels is associated with minor regional stress and strain but increased shunt (higher red bands in dark blue areas). Low tidal volume (VT) at zero PEEP results in minimally increased transpulmonary pressure in the ventral while no changes in the dorsal regions at end-inspiration, minimizing overdistension and tidal recruitment. $\mathbf{b}$ Increased airway pressures promote alveolar recruitment, but increased regional stress and strain in the most dependent lung regions, with possible hemodynamic effects; high tidal volume at zero PEEP results in increased transpulmonary pressure in the ventral and dorsal regions at end-inspiration, increasing the ventilation/perfusion ratio (light blue and narrow red bands) with overdistension and tidal recruitment. On the other hand, increased shunt at end-expiration. c Ventilation at moderate PEEP levels optimizes the regional transpulmonary pressures as well as ventilation-perfusion. Low VT with moderate PEEP levels increases lung recruitment (light blue area) while still avoiding dynamic overdistension maximizing improvement in shunt (light blue and red bands). d Ventilation at excessively high PEEP levels increases regional transpulmonary pressures and stress and strain with vascular compression (light blue area and narrow red bands) resulting in negative hemodynamic effects and low tidal volume with higher PEEP levels, while ensuring maximal lung recruitment, causes ventral overdistension at end-inspiration and end-expiration
\end{abstract}

obese patients [27]. To limit desaturation during the intubation procedure, preoxygenation must be optimized. A preoxygenation of 5 min with noninvasive ventilation (NIV) in a sitting position, associating pressure support and positive end-expiratory pressure (PEEP) permits reaching an exhaled fraction in oxygen $>90 \%$ more quickly than standard bag valve mask ventilation in obese patients [28]. The OPTINIV preoxygenation technique [associating a high-flow nasal cannula (HFNC) with NIV] was more effective at reducing oxygen desaturation compared with the reference method using NIV alone in a randomized controlled trial including obese and nonobese patients with severe acute respiratory failure [29].

\section{Invasive mechanical ventilation}

\section{In non-ARDS}

As in non-obese patients, protective ventilation should be applied in obese patients, using low tidal volume [set according to ideal body weight (IBW)], moderate-to-high PEEP and recruitment maneuvers [22]. The respiratory mechanics, alveolar recruitment and gas exchanges are significantly improved by application of PEEP $\geq 10 \mathrm{cmH}_{2} \mathrm{O}$ (improvement of respiratory compliance and decrease of inspiratory resistance) [30]. However, commonly used PEEP by clinicians $\left(11.6 \pm 2.9 \mathrm{cmH}_{2} \mathrm{O}\right)$ was shown inadequate for minimizing atelectasis and "optimizing" ventilation in obese ICU patients [31]. A recruitment maneuver followed by PEEP titration significantly improved lung volumes, respiratory system elastance and oxygenation. Optimal PEEP levels were around $20 \mathrm{cmH}_{2} 0$. More recently, a PEEP of $12 \mathrm{cmH}_{2} \mathrm{O}$ was found adequate to minimize atelectasis as monitored by electric impedance tomography in obese patients [32]. Another study [33] highlighted the positive impact of recruitment maneuvers on arterial oxygenation and available lung volume in the obese patient. However, higher PEEP levels have not been clearly shown to minimize clinically relevant complications and might impair hemodynamics, with additional need of vasoactive drugs, as well as fluid overload. Furthermore, recruitment performed by bag squeezing during surgery was associated with increased risk of postoperative pulmonary complications [34]. Thus, recruitment, when needed, should be performed under ventilator control [35].

\section{In ARDS}

High PEEP has been reported to be associated with better survival in obese patients with ARDS [36]. Contrary to non-obese patients, driving pressure might not be appropriated to assess the severity and prognosis of obese ARDS patients [37]. Of interest, low-to-negative values of transpulmonary pressure predict lung collapse and intratidal recruitment/derecruitment in obese patients [38]. These results further support the monitoring of transpulmonary pressure using esophageal pressure even if future studies are needed to demonstrate its safety and efficiency in obese patients with ARDS.

Figure 2 shows the effects of different airway pressures at end-inspiration and expiration on regional transpulmonary pressure as well as aeration and atelectasis.

Prone position is a therapy of choice in obese ARDS patients. The safety and efficiency of prone position in ARDS patients with a body mass index $>35 \mathrm{~kg} / \mathrm{m}^{2}$ were found similar to those of non-obese patients, the ratio of arterial oxygen pressure and the fraction of inspired oxygen $\left(\mathrm{PaO}_{2} / \mathrm{FiO}_{2}\right)$ being even significantly more increased after prone position in obese patients compared with non-obese patients [39]. Reverse Trendelenburg position and optimal abdominal fat positioning can help to avoid complications of increased abdominal pressure as bowel ischemia. In case of severe ARDS 


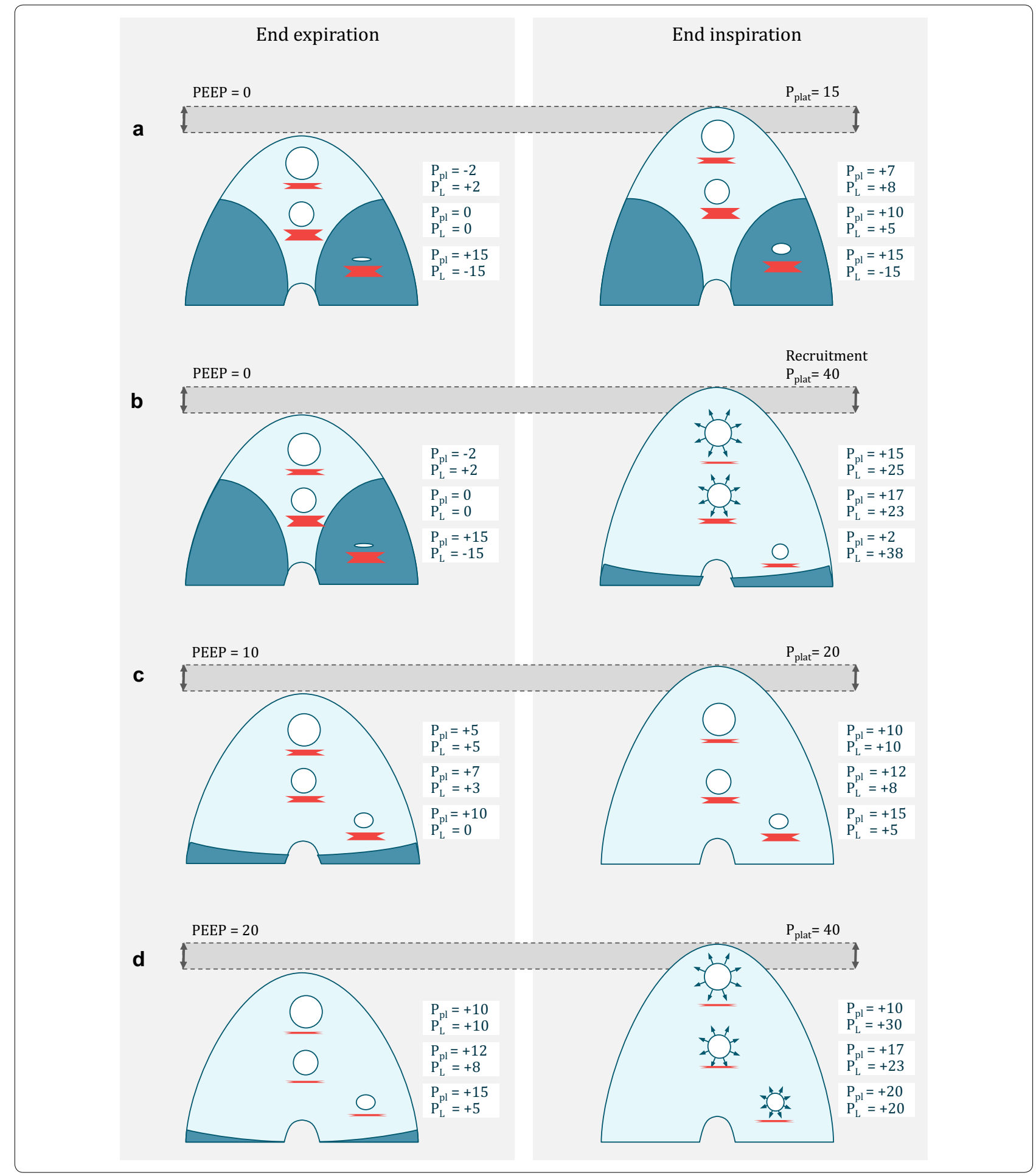

after failure or impossibility of using prone positioning and neuromuscular blockers, veno-venous extracorporeal membrane oxygenation (ECMO) can also be safely used in obese ARDS patients [40].
Noninvasive support therapy (oxygen therapy, noninvasive ventilation and CPAP)

NIV and continuous positive airway pressure (CPAP) have proven effective in small observational studies in preventing acute respiratory failure following extubation 
Table 2 Ventilatory management in obese non-ARDS and ARDS patients

\begin{tabular}{|c|c|c|}
\hline Intubation & $\begin{array}{l}\operatorname{CPAP}\left(5-10 \mathrm{~cm} \mathrm{H}_{2} \mathrm{O}\right) \\
\text { or } \\
\mathrm{NIV}\left(\mathrm{PS} 10 \mathrm{cmH}_{2} \mathrm{O} \text { and PEEP } 5-10 \mathrm{cmH}_{2} \mathrm{O}\right) \\
\text { or } \\
\text { HFNC }(40-60 \mathrm{l} / \mathrm{min}) \text { and NIV }\left(\mathrm{FiO}_{2} 0.8-1\right)\end{array}$ & \\
\hline Mechanical ventilation & $\begin{array}{l}\text { No ARDS } \\
\text { TV }(6 \mathrm{ml} / \mathrm{kg} \mathrm{IBW}) \\
\text { RR to achieve } \mathrm{CO}_{2} 35-45 \mathrm{mmHg} \text { or individual } \mathrm{ETCO}_{2} \text { or } \\
\text { pH }>7.25 \\
\text { PEEP } 5-10 \mathrm{cmH}_{2} \mathrm{O} \text { or individualized according to oxygenation, } \\
\text { driving or transpulmonary pressure } \\
\text { Pplat }<20 \mathrm{cmH}_{2} \mathrm{O} \\
\text { Driving pressure }<15 \mathrm{cmH}_{2} \mathrm{O} \\
\text { Recruitment } \mathrm{maneuvers} \mathrm{only} \mathrm{if} \mathrm{clinically} \mathrm{needed}_{\mathrm{FiO}_{2} \text { to keep } \mathrm{SpO}_{2} 92-95 \%}\end{array}$ & $\begin{array}{l}\text { ARDS } \\
\text { Tidal volume }(6 \mathrm{ml} / \mathrm{kg} \mathrm{IBW}) \\
\mathrm{RR} \text { to achieve } \mathrm{ETCO}_{2} 35-45 \mathrm{mmHg} \text { or individual } \mathrm{ETCO}_{2} \text { or } \\
\mathrm{pH}>7.25 \\
\text { PEEP } 10-15 \mathrm{cmH}_{2} \mathrm{O} \text { or individualized according to optimal } \\
\text { oxygenation, driving or transpulmonary pressure } \\
\text { Pplat }<30 \mathrm{cmH}_{2} \mathrm{O} \\
\text { Driving pressure }<15 \mathrm{cmH}_{2} \mathrm{O}, \\
\text { Recruitment maneuvers }\left(40-50 \mathrm{cmH}_{2} \mathrm{O}\right) \text { only if clinically } \\
\text { needed and/or before PEEP setting } \\
\text { FiO to keep } \mathrm{SpO}_{2} 92-95 \% \\
\text { Prone position if } \mathrm{PaO}_{2} / \mathrm{FiO}_{2}<150 \mathrm{mmHg} \text { to } \\
\text { Use NIV cautiously and do not delay intubation }\end{array}$ \\
\hline Extubation & \multicolumn{2}{|c|}{$\begin{array}{l}\text { CPAP or NIV after extubation, especially in patients with comorbidities and/or OSAHS with or without home ventilation } \\
\text { and/or cardiac diseases; in patients with intraoperative oxygen desaturation and/or hemodynamic impairment and/or } \\
\text { admission to high-dependency units }\end{array}$} \\
\hline
\end{tabular}

ARDS acute respiratory distress syndrome, CPAP continuous positive airway pressure, NIV non-invasive ventilation, $H F N C$ high-flow oxygen nasal cannula, IBW ideal body weight [for males: $0.9 \times$ (height in $\mathrm{cm}-100$ ), for females: $0.9 \times$ (height in $\mathrm{cm}-106$ )], $R R$ respiratory rate, $P a C \mathrm{CO}_{2}$ arterial pressure of carbon dioxide $\left(\mathrm{CO}_{2}\right), E T C \mathrm{O}_{2}$ end tidal $\mathrm{PCO}_{2}$, Pplat plateau pressure of the respiratory system, $\mathrm{FiO}_{2}$ inspired oxygen fraction, $\mathrm{SpO}_{2}$ peripheral capillary oxygen saturation, OSAHS obstructive sleep apnea and hypoventilation syndrome

of obese patients in the ICU and postoperative setting $[21,22]$. A high-flow oxygen nasal cannula (HFNC) was not found superior to standard oxygen to prevent reintubation in 155 obese post-cardiac surgery patients [41]. In case of acute hypercapnic respiratory failure, curative NIV is as efficient in patients presenting an obesity hypoventilation syndrome as in chronic obstructive pulmonary disease patients [42]. In the absence of a large study in obese ARDS patients, NIV should be used with caution in this specific population. Among obese cardiothoracic surgery subjects with or without respiratory failure, the use of continuous HFNC compared with NIV did not result in more treatment failure [43]. Whatever the method of oxygenation chosen (NIV, CPAP, HFNC, standard oxygen), intubation should not be delayed in obese ARDS patients (Table 2).

\section{Future agenda for ventilation In non-ARDS}

For airway management, preoxygenation using HFNC, and the use of video laryngoscopes in obese patients should be evaluated in large randomized controlled studies. The best mechanical ventilation settings to prevent ARDS occurrence must be determined. The benefit of post-extubation preventive NIV \pm HFNC compared with standard oxygen therapy to prevent reintubation remains to be assessed in overall obese ICU patients.

\section{In ARDS}

The optimal mechanical ventilation settings in ARDS obese patients are still unknown, morbid obesity being often an exclusion criterion in the main ARDS studies. The best indications for using extracorporeal membrane oxygenation (ECMO) and extracorporeal carbon dioxide removal $\left(\mathrm{ECCO}_{2} \mathrm{R}\right)$ in obese patients need to be investigated.

\section{The cardiovascular system}

Obese patients, depending on the degree, distribution and duration of obesity, are at increased risk of developing cardiovascular disease. Fat mass-related cardiovascular pathology includes increased blood volume and cardiac output, with secondary ventricular hypertrophy and diastolic dysfunction and finally ventricular dilation (obesity cardiomyopathy). Atrial fibrillation is a frequent complication of obesity, and pulmonary hypertension (secondary to elevated left atrial pressure, hypoxia from obstructive sleep apnea and hypoventilation syndrome or chronic thromboembolism) should also be suspected. In addition to fat mass-related problems, sick fat (visceral and ectopic fat) can affect the cardiovascular system through direct immune and endocrine effects or indirectly by the associated metabolic syndrome with hypertension (afterload), dyslipidemia and ischemic cardiopathy [2].

In view of the high cardiovascular risks, accurate hemodynamic monitoring is crucial, but may be challenging in obese patients. Oscillometric blood pressure 
measurements are less accurate in obesity [44], and invasive blood pressure monitoring should be the standard in hemodynamically unstable patients. Transthoracic echocardiography often suffers from a poor acoustic window hampering accurate image acquisition. Evaluation of hemodynamic instability may require transesophageal echocardiography. Uncalibrated noninvasive cardiac output measurement based on pulse contour analysis has gained popularity in the ICU but appears inaccurate in obese patients [45]. This is not surprising since the transformation of the pressure wave form to a cardiac output relies on an algorithm including the dynamic characteristics of the vessel wall that may be significantly altered in obesity. If close monitoring of cardiac output is considered necessary, right heart catheterization or esophageal Doppler could be used. Limited data are available on the interpretation of hemodynamic parameters in obesity: a small study suggests it should not be different from nonobese patients on the condition that they are indexed to the body surface area.

Fluid resuscitation in the obese should account for both the increased blood volume and the risk of fluid overload and heart failure. Little guidance exists for initial fluid resuscitation in obese patients, and the surviving sepsis campaign does not mention this subgroup. Two studies in trauma [46] and septic shock [47] showed that obese patients received less fluid on a weight basis and had more persistent shock or needed more escalation of hemodynamic support and time to reach stability, potentially pointing to under-resuscitation. Similarly, using ideal body weight to guide fluid resuscitation prolonged metabolic acidosis in obese trauma patients [48]. A retrospective analysis of a large cohort of patients with suspected sepsis suggested that using an adjusted body weight to guide initial resuscitation may result in better outcomes than actual or ideal body weight [49]. There is no doubt that fluid resuscitation should be performed with even more cautiousness compared with non-obese patients. Regarding dosing of vasoactive drugs, a retrospective analysis in obese patients with septic shock showed a lower weight-based but similar absolute norepinephrine requirement [50] suggesting that vasoactive drugs should be titrated to their clinical effect rather than using weight-based dosing.

\section{The kidney}

In the past decade obesity was recognized as an important cause and cofactor in the development and progression of chronic kidney disease. This fact has been termed "obesity-related nephropathy" [51]. The association of BMI and renal injury is multifactorial. The increased renal perfusion and glomerular hyperfiltration augments intraglomerular pressure, sodium reabsorption and metabolic demands leading to glomerulomegaly and focal or segmental sclerosis [52]. Moreover, obesity is associated with insulin resistance, type 2 diabetes and hypertension, all important risk factors for chronic kidney disease.

Obesity also appears to be an independent risk factor for acute kidney injury (AKI) [53]. There is a linear correlation between BMI and the incidence of AKI, with higher BMI being associated with higher incidence [53]. The underlying mechanisms have been incompletely established, but besides obesity-associated comorbidities (especially chronic kidney disease), endocrine effects of adipose tissue may play a role. Additional obesity-related AKI risk factors include increases in central venous pressure and intra-abdominal pressure [54].

Despite the increased risk of AKI in obese patients, once AKI occurs, the previously discussed "obesity paradox," with lower mortality rates in obese patients, has also been described in AKI [53] and chronic kidney disease [10]. In renal dysfunction, this survival advantage may have some specific explanations, such as higher plasma concentrations of beneficial mediators, an improved hemodynamic stability during renal replacement therapy and potentially fat tissue serving as a "buffer" for uremic toxins [52]. The survival advantage in obese compared with non-obese AKI patients may, however, be offset by the increased incidence of AKI, which by itself is a risk factor for mortality.

Obesity may also represent a problem for the diagnosis and supportive therapy of AKI. Using actual body weight to apply the oliguria criteria may lead to a false-positive diagnosis of AKI. In addition, it is not clear whether dosing continuous renal replacement therapy on a $\mathrm{ml} / \mathrm{kg} / \mathrm{h}$ basis should use actual, adjusted or ideal body weight (formulas shown in Table 3 legend).

\section{Immunity and infection}

While it is increasingly recognized that adipose tissue is an active participant in the regulation of physiologic and pathologic processes, including immunity and inflammation, the evidence on how and to what extent obesity influences the immune response and the subsequent clinical outcome remains complex and conflicting. Clearly, there is cross-talk between immune cells and adipocytes, resulting in the (dys)regulation of both innate and adaptive immunity [18] (Fig. 3). Adipose tissue produces several hormones (adipokines) and classical inflammatory mediators resulting in chronic inflammation [18], as illustrated by elevated baseline CRP levels in obese patients [55]. Of interest, and illustrating the complex interplay of covariates present in obesity, it has become clear that this chronic inflammation plays a role in the development of 
Table 3 Summary of the ESPEN and ASPEN guidelines for adjustment of nutritional therapy in critically ill obese patients

\begin{tabular}{|c|c|c|}
\hline Suggestions & ESPEN guidelines & ASPEN guidelines \\
\hline \multicolumn{3}{|c|}{ For calculating the energy target if measurement of REE is not possible } \\
\hline In general & $\begin{array}{l}20-25 \mathrm{kcal} / \mathrm{kg} \text { actual BW/day } \\
\text { Below } 70 \% \text { of REE should be given during 'early' acute } \\
\text { phase }\end{array}$ & 25-30 kcal/kg actual BW/day \\
\hline In obese & $\begin{array}{l}\text { Same as above, but calculated according to adjusted BWa } \\
\text { If REE measured, set target to } 80-100 \% \text { of REE after the } \\
\text { early acute phase (within days 3-7) }\end{array}$ & $\begin{array}{l}11-14 \mathrm{kcal} / \mathrm{kg} \text { actual BW/day } \\
\text { if BMl } 30-50 \mathrm{~kg} / \mathrm{m}^{2} \\
22-25 \mathrm{kcal} / \mathrm{kg} \text { ideal BW} / \text { day } \\
\text { if BMl }>50 \mathrm{~kg} / \mathrm{m}^{2} \\
\text { If REE measured, set target to } \\
65-70 \% \text { of REE }\end{array}$ \\
\hline \multicolumn{3}{|c|}{ For calculating protein target } \\
\hline In general & $1.3 \mathrm{~g} / \mathrm{kg}$ actual BW/day & $1.2-2.0 \mathrm{~g} / \mathrm{kg}$ actual BW/day \\
\hline In obese & Same as above, but calculated with adjusted BWa & $2.0-2.5 \mathrm{~g} / \mathrm{kg}$ ideal BWb/day \\
\hline \multicolumn{3}{|c|}{ For adjustment of nutritional therapy according to serum markers ${ }^{c}$} \\
\hline Glucose & $\begin{array}{l}\text { Below } 10 \mathrm{mmol} / \mathrm{l}(180 \mathrm{~g} / \mathrm{l}) \\
\text { Consider lowering carbohydrate administration when }>6 \mathrm{U} \\
\text { insulin/h is needed for }>24 \mathrm{~h}\end{array}$ & Below $10 \mathrm{mmol} / \mathrm{l}(180 \mathrm{~g} / \mathrm{l})$ \\
\hline Urea & $\begin{array}{l}\text { Consider lowering protein administration if }>30 \mathrm{mmol} / \mathrm{l} \text { : } \\
\text { Probably only justified if protein administration }>1.5 \mathrm{~g} / \mathrm{kg} \\
\text { BW/day }\end{array}$ & - \\
\hline Triglycerids & $\begin{array}{l}\text { Investigate and consider lowering fat administration } \\
\text { if }>5.6 \mathrm{mmol} / /\end{array}$ & - \\
\hline \multicolumn{3}{|c|}{ Examples for calculating energy and protein targets in obese ${ }^{d}$} \\
\hline \multicolumn{3}{|c|}{$\begin{array}{l}\text { Example 1: male } 120 \mathrm{~kg}, 185 \mathrm{~cm} \geq \mathrm{BMI}=35.1 \mathrm{~kg} / \mathrm{m}^{2} \\
\text { Ideal } \mathrm{BW}^{\mathrm{b}}=77 \mathrm{~kg}^{\mathrm{b}} \text { and adjusted } \mathrm{BW}^{\mathrm{a}} 86-88 \mathrm{~kg}\end{array}$} \\
\hline Energy target & $\begin{array}{l}\text { Calculated with adjusted BW } \\
25 \mathrm{kcal} \times 86-88 \mathrm{~kg} \\
\text { Target }=2150-2200 \mathrm{kcal} / \text { day }\end{array}$ & $\begin{array}{l}\text { Calculated with actual BW } \\
14 \mathrm{kcal} \times 120 \mathrm{~kg} \\
\text { Target }=1680 \mathrm{kcal} / \text { day }\end{array}$ \\
\hline Protein target & $\begin{array}{l}\text { Calculated with adjusted } \mathrm{BW}^{\mathrm{a}} \\
1.3 \mathrm{~g} \times 92-96 \mathrm{~kg}^{\mathrm{a}} \\
\text { Target }=120-125 \mathrm{~g} / \text { day }\end{array}$ & $\begin{array}{l}\text { Calculated with ideal BW } \\
2.0-2.5 \mathrm{~g} \times 77 \mathrm{~kg}^{\mathrm{b}} \\
\text { Target }=154-193 \mathrm{~g} / \text { day }\end{array}$ \\
\hline \multicolumn{3}{|c|}{$\begin{array}{l}\text { Example 2: female } 140 \mathrm{~kg}, 165 \mathrm{~cm} \geq \mathrm{BMI}=51.5 \mathrm{~kg} / \mathrm{m}^{2} \\
\text { Ideal } \mathrm{BW}^{\mathrm{b}}: 53 \mathrm{~kg} \text { and adjusted } \mathrm{BW}^{\mathrm{a}}=70-75 \mathrm{~kg}\end{array}$} \\
\hline Energy target & $\begin{array}{l}\text { Calculated with adjusted BW } \\
25 \mathrm{kcal} \times 70-75 \mathrm{~kg} \\
\text { Target }=1750-1875 \mathrm{kcal} / \text { day }\end{array}$ & $\begin{array}{l}\text { Calculated with ideal } \text { BW }^{\text {b }} \\
25 \mathrm{kcal} \times 53 \mathrm{~kg} \\
\text { Target }=1325 \mathrm{kcal} / \text { day }\end{array}$ \\
\hline Protein target & $\begin{array}{l}\text { Calculated with adjusted BW } \\
1.3 \mathrm{~g} \times 70-75 \mathrm{~kg} \\
\text { Target }=91-98 \mathrm{~g} / \text { day }\end{array}$ & $\begin{array}{l}\text { Calculated with ideal } \mathrm{BW}^{\mathrm{b}} \\
2.0-2.5 \mathrm{~g} \times 53 \mathrm{~kg} \\
\text { Target }=106-133 \mathrm{~g} / \text { day }\end{array}$ \\
\hline
\end{tabular}

$R E E$ resting energy expenditure, $B W$ body weight

a Adjusted BW =ideal BW $+20-25 \%$ of difference between actual and ideal BW (actual BW - ideal BW)

b Ideal BW: for males: $0.9 \times$ (height in $\mathrm{cm}-100$ ); for females: $0.9 \times$ (height in $\mathrm{cm}-106$ ) suggested in ESPEN guidelines, no specific suggestion for calculating ideal BW in ASPEN guidelines

c No difference in guideline targets regardless of whether applied to normal weight or obese individuals

$\mathrm{d}$ The upper level of suggested energy targets in $\mathrm{kcal} / \mathrm{BW} /$ day is taken as a basis for calculations

insulin resistance and the cardiovascular complications of obesity $[7,18]$.

While chronic inflammation is present, there are indications that the innate immune response is impaired in obese patients. The association between severe obesity and both community-acquired and nosocomial infection has indeed repeatedly been described [56], although it is not a universal finding [4]. Also, adaptive immunity appears affected. Following influenza vaccination, the initial response (IgG levels) may be more pronounced, but 1 year later antibody titers were lower in obese patients compared with the non-obese [57]. In addition, obesity was found to be an independent risk factor for increased morbidity and mortality from pandemic H1N1 infection [58]. The effect of obesity on the adaptive immune response appears also to be mediated through perturbations in $\mathrm{T}$ cell numbers, metabolism 


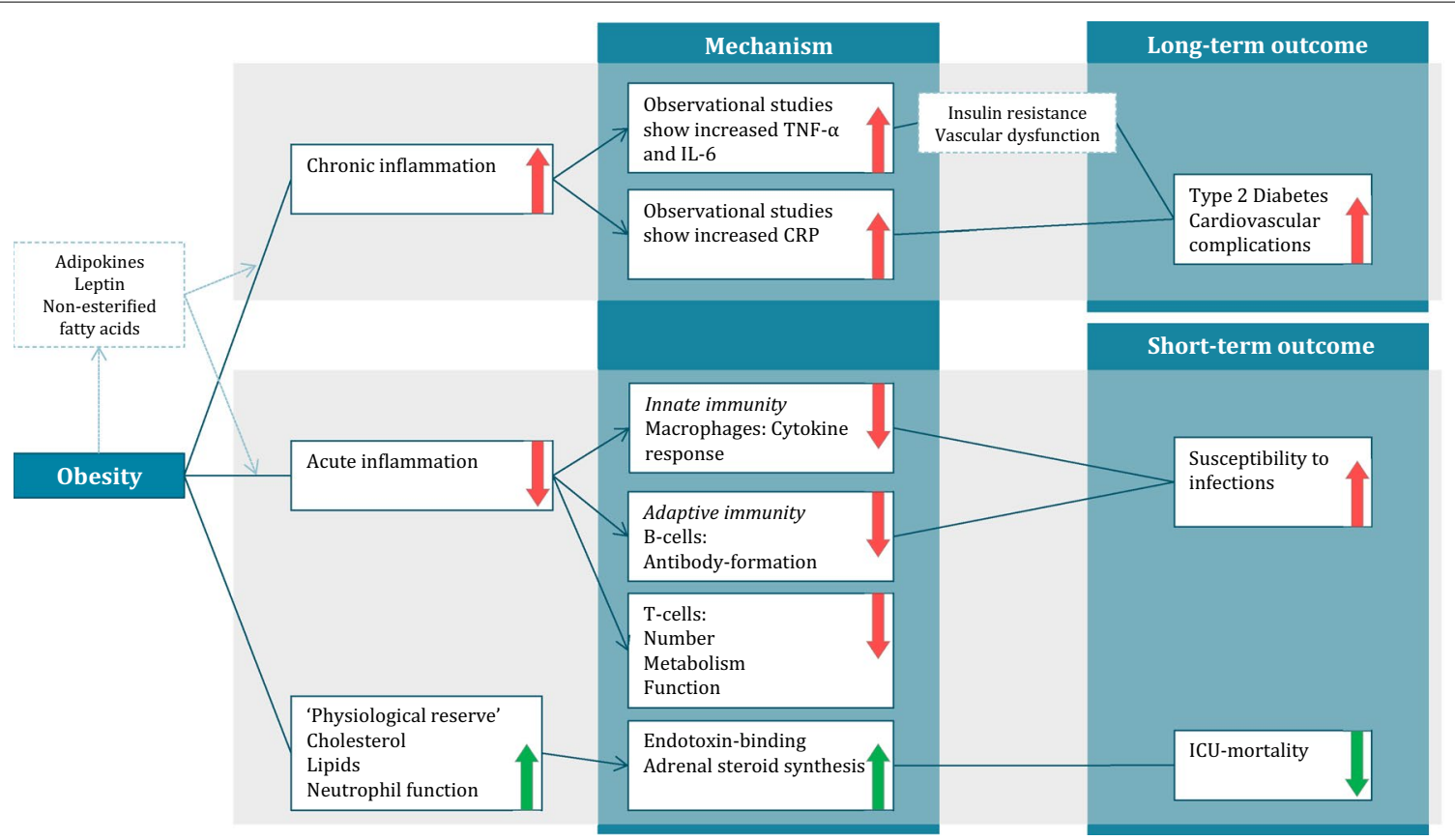

Fig. 3 Immune effects of obesity. Obesity exerts different effects on the immune system, at least partly mediated through adipokines, leptin and non-estherified fatty acids. Observational studies indicate that obese patients are chronically inflamed, as they have elevated concentrations of different cytokines and c-reactive protein. In the long term, this is related to the development of insulin resistance and vascular dysfunction, eventually contributing to the development of type 2 diabetes and cardiovascular complications more frequently observed in obese patients. There are also acute effects of obesity on inflammation. Both innate (cytokine production) and adaptive (e.g., antibody formation) immunities appear inhibited in obese patients. In addition, T-cells may be negatively affected in number and function. These acute effects on immunity may account for the observed increased susceptibility to infection in obese patients. Despite this higher susceptibility to infections, clinical outcome in obese patients is better. It is currently unclear what the mechanism of this observation might be. Obese patients might have more physiologic reserve to overcome a katabolic period, but also a higher lipid concentration may result in endotoxin binding or more adrenal steroid synthesis reserve

and functioning [59]. Nutrient, hormone and adipokine dysregulations in the obese patient may be implicated. Despite the evidence supporting the notion that obesity impairs immunologic responses and increases the susceptibility to become infected, the "obesity paradox" has also been described in patients with pneumonia and sepsis [11]. Overall, it appears that obesity is associated with chronic inflammation and several impairments in immunity, while the clinical outcome following an infection is not negatively influenced.

\section{Other issues}

Other obesity-related problems in ICU patients include increased risk of venous thromboembolism (VTE), both deep vein thrombosis and pulmonary embolism (PE) [60], abdominal compartment syndrome and skin problems. The mechanisms underlying the increased VTE risk are multiple. Obesity, especially visceral obesity, results in a proinflammatory, prothrombotic and hypofibrinogenic milieu [7]. Besides physical effects of body fat, limiting venous return and causing stasis, the underlying pathology leading to critical illness (e.g., sepsis), the associated bed rest and possible subtherapeutic thrombosis prophylaxis may further increase the prothrombotic state. Diagnosis of VTE is difficult and particularly challenging in the obese. Clinical signs such as leg swelling may be obscured, and compression ultrasonography is hindered by the increased soft tissue thickness [60]. Other imaging procedures are often limited by the equipment (see below).

Optimal dosing of prophylactic anticoagulants in obesity is poorly documented [61]. Normal fixed doses of low-molecular-weight heparin (LMWH) may be inadequate. In small studies, inverse correlations have been found between body weight and anti-Xa levels [61]. For enoxaparin, both increased fixed doses (40 or $60 \mathrm{mg}$ twice a day or $60 \mathrm{mg}$ once a day) and weightbased dosing $(0.5 \mathrm{mg} / \mathrm{kg}$ once or twice a day) have been suggested [61]. Most of these studies used the anti-Xa level (target peak $0.3-0.5 \mathrm{U} / \mathrm{ml}$ ) as a surrogate outcome. However, monitoring of anti-Xa in clinical practice remains controversial [61]. The evidence for intermittent pneumatic compression is limited [61], and early ambulation remains important. 
Immobilization of obese patients, especially the morbidly obese, increases the risk of skin breakdown and decubitus ulcers. Pressure-reducing devices and patient positioning are therefore of utmost importance but challenging.

\section{Nutrition}

Despite the clear role of nutrition in development of obesity, there is considerable uncertainty as to optimal nutritional therapy for obese people during critical illness. Obesity defined by BMI (Table 1) may occur with increased, normal or low muscle mass. Low muscle mass or sarcopenia occurs mainly with aging and may be substantial and not immediately obvious in the critically ill patient with a higher BMI [1]. Body composition (relative muscle and fat mass) has a stronger relationship with outcomes than BMI per se [62].

Independent of body constitution, the preferred route to provide nutritional therapy is enteral [63-65]. The estimation of caloric and protein requirements in critically ill obese patient may require an alternative approach to that used for 'normal' BMI patients. Furthermore, the underlying metabolic syndrome may require more intensified monitoring of hyperglycemia and hyperlipidemia.

Equations estimating resting energy expenditure (REE) are even more imprecise in obese patients. International guidelines therefore recommend measuring REE with indirect calorimetry in obese patients [64]. However, since indirect calorimetry is not always available, calculations remain a pragmatic estimate of energy expenditure, particularly in the acute phase of illness, to set target energy delivery (Table 2).

The American Society for Parenteral and Enteral Nutrition (ASPEN) guidelines recommend $65-70 \%$ of REE be delivered to obese patients and propose using either 11-14 kcal/kg actual body weight/day (for BMI $30-50 \mathrm{~kg} / \mathrm{m}^{2}$ ) or $22-25 \mathrm{kcal} / \mathrm{kg}$ ideal body weight/day (for BMI $>50 \mathrm{~kg} / \mathrm{m}^{2}$ ) to calculate this target [63]. The European Society for Clinical Nutrition and Metabolism (ESPEN) guidelines [64] recommend 20-25 kcal/kg adjusted body weight/day with no further adjustments below REE in obese patients after the early acute phase (Table 3).

The optimal amount of protein to deliver to obese critically ill patients is also contentious. ASPEN guidelines suggest a hypocaloric high protein diet with $2.0-2.5 \mathrm{~g} /$ $\mathrm{kg}$ ideal body weight/day [63], whereas the ESPEN guidelines do not support such high protein supply and recommend $1.3 \mathrm{~g} / \mathrm{kg}$ of "adjusted body weight"/day (Table 3) [64]. Similar to starvation, in obese ICU patients the percentage of protein oxidation contributing to basal metabolic rate may be reduced with an increased utilization of ketone bodies [66]. Excess energy storage in fat tissue may therefore attenuate muscle wasting during critical illness [66]. In older obese critically ill patients, a hypocaloric high-protein feeding increased blood urea concentrations [67], suggesting that high-protein feeding may not be appropriate for all patients. ESPEN guidelines suggest assessment of lean body mass and nitrogen balance in obese patients, whereas no specific recommendations for monitoring and management of glucose, urea or triglycerids are provided [64]. A more nuanced understanding of metabolism in the obese critically ill may inform future design of specialized nutritional therapies [68]. Until then, we support using a pragmatic approach as suggested in ESPEN guidelines [64].

\section{Pharmacotherapy}

Obesity can affect pharmacokinetics (relationship between drug dose and concentrations in the body) as well as pharmacodynamics (the pharmacologic effect resulting from a drug's concentration). This is of potential major significance as most drugs elicit a strong concentration-effect relationship and dosing regimens are developed without consideration of the pathophysiologic effects of critical illness or obesity on pharmacokinetics.

Predicting the need for dose adjustment relies on an understanding of the physicochemistry of the drug (hydrophilic or lipophilic) and the effect that obesity itself, or critical illness, can have on altering pharmacokinetics and dosing requirements. Hydrophilic drugs mostly distribute into water-based sites in the body (e.g., interstitial fluid, muscle), whereas lipophilic drugs are more likely to distribute intracellularly and into adipose tissue. Where altered pharmacokinetics lead to an increased volume of distribution $(\mathrm{Vd})$, this may lead to a requirement for greater doses, whereas changes to drug clearance can require a different dosing frequency.

\section{Pharmacokinetic changes associated with obesity}

The increased body weight associated with obesity is likely to affect the Vd of all drugs [69]. Hydrophilic drugs will have a small increase in $\mathrm{Vd}$ as a result of an increased blood volume and an increased lean muscle mass. Lipophilic drugs are more likely to distribute into the increased volume of adipose tissue, which will increase their Vd. For drugs with weight-based dosing, choosing the most relevant weight metric may be difficult. Almost always a lean body weight descriptor, including adjusted body weight, is likely to be more relevant than ideal body weight or actual body weight for both hydrophilic and lipophilic drugs alike [70]. It is rare that a dosing weight > $100 \mathrm{~kg}$ is ever required. It is important to note the importance that comorbidities may be present in patients with long-standing obesity (e.g., peripheral vascular disease, 
chronic kidney disease, non-alcoholic fatty liver disease), as these may affect the pharmacokinetics as well.

\section{Pharmacokinetic alterations caused by critical illness}

There are many small studies describing the scenarios and drugs where critical illness may affect pharmacokinetics [71]. Principally, for renally cleared and hydrophilic drugs (low Vd), the effects vary from very high drug clearances (augmented renal clearance) to difficultto-predict effects on drug clearance in the presence of renal replacement therapy and extracorporeal membrane oxygenation. Hypoalbuminemia may affect drug clearance for some drugs with high protein binding (e.g., ceftriaxone, phenytoin) as well as the Vd of hydrophilic drugs. However, the latter will be more affected by highvolume fluid resuscitation.

In summary, the magnitude of any altered pharmacokinetics in critically ill obese patients is generally driven by the presence of critical illness, with obesity itself being a lesser contributor. Because of the multiplicity of factors affecting drug levels, a one-size-fits-all approach is not justified, and maximal use of therapeutic drug monitoring is recommended.

\section{Diagnostic and logistic challenges}

Peripheral veins are often less accessible in obese patients. In addition, due to the absence of anatomical landmarks, establishing a central venous access may be particularly challenging. Ultrasound guidance should be the standard of care. Not unexpectedly, a femoral access has been shown to increase the risk of infection in this population [72]. Diagnostic investigations often yield reduced image quality due to the limited penetration of portable X-ray machines and ultrasound waves. Also, transporting the patient to the radiology department may be challenging. CT and MRI are limited by the aperture diameter of the equipment and the table weight limit. In addition, they require a supine position, which may cause respiratory difficulties.

Morbid obesity affects nursing workload and resource use. Indeed, caring for the obese will frequently require additional staff (some even suggest dedicated teams), staff training and specialized durable equipment (bariatric beds, mattresses, transfer devices, lifts, chairs, walkers) to enable safe care for both the patient and staff. Despite specialized equipment, early in-ICU mobilization and post-ICU rehabilitation of obese patients remain challenging.

\section{Psychologic aspects}

Health care workers are not immune to the social stigma of obesity, with negative attitudes and prejudices towards obese patients. People living with obesity are often perceived as weak-willed, unmotivated, noncompliant, sloppy and accountable for their excess weight. In the ICU, nurses provide physically and emotionally demanding care to these patients with complex needs. A qualitative study among ICU nurses showed feelings of repulsion, disgust, anger, frustration, blame, discomfort and fear despite the intention to provide obese patients with the same level of care as normal weight patients [73]. These negative attitudes impact the obese patient both physically and psychologically with feelings of embarrassment, discrimination and distress [74]. Providing nurses with the appropriate equipment and infrastructure to alleviate the physical burden of caring for obese patients, increasing awareness of the impact of their attitudes and specific education, may help to systemically improve the health care experience for obese patients [74].

\section{Conclusion}

Obesity is associated with important health risks. It affects one-fifth of ICU patients. Although moderate obesity may paradoxically decrease mortality in ICU patients, increased adipose tissue has an impact on several organ systems, increases morbidity and requires an adapted ICU management, which is summarized in Fig. 1.

\section{Author details}

${ }^{1}$ Division of Cellular and Molecular Medicine, Clinical Department and Laboratory of Intensive Care Medicine, KU Leuven University, Herestraat 49, 3000 Leuven, Belgium. ${ }^{2}$ Anesthesia and Critical Care Department (DAR-B), Saint Eloi, University of Montpellier, Research Unit: PhyMedExp, INSERM U-1046, CNRS, 34295 Montpellier Cedex 5, France. ${ }^{3}$ Department of Medicine and Radiology, Melbourne Medical School, Royal Melbourne Hospital, The University of Melbourne, Parkville, VIC, Australia. ${ }^{4}$ Department of Medicine (Royal Melbourne Hospital), University of Melbourne, Parkville, VIC, Australia. ${ }^{5}$ Klinik für Innere Medizin III, Abteilung für Nephrologie, Allgemeines Krankenhaus Wien, Währinger Gürtel 18-20, 1090 Vienna, Austria. ${ }^{6}$ Department of Intensive Care Medicine (710), Radboud University Medical Centre, Geert Grooteplein Zuid 10, P.O. Box 9101, 6500 HB Nijmegen, The Netherlands. ${ }^{7}$ Department of Surgical Sciences and Integrated Diagnostics, University of Genoa, Genoa, Italy. ${ }^{8}$ Anesthesia and Intensive Care, San Martino Policlinico Hospital, IRCCS for Oncology and Neurosciences, Genoa, Genoa, Italy. ${ }^{9}$ Radboud Center for Infectious Diseases, Nijmegen, The Netherlands. ${ }^{10}$ Department of Intensive Care Medicine, Lucerne Cantonal Hospital, Lucerne, Switzerland. ${ }^{11}$ Department of Anaesthesiology and Intensive Care, University of Tartu, Tartu, Estonia. ${ }^{12}$ University of Queensland Centre for Clinical Research, Faculty of Medicine, University of Queensland, Herston, Australia. ${ }^{13}$ Centre for Translational Anti-infective Pharmacodynamics, School of Pharmacy, The University of Queensland, Woolloongabba, Australia. ${ }^{14}$ Pharmacy Department, Royal Brisbane and Women's Hospital, Brisbane, Australia. ${ }^{15}$ Departments of Intensive Care Medicine, Royal Brisbane and Women's Hospital, Brisbane, Australia.

${ }^{16}$ Department of Anesthesiology and Intensive Care, Uniklinikum Jena, Jena, Germany.

\section{Compliance with ethical standards}

\section{Conflicts of interest}

Dr. Jaber reports receiving consulting fees from Drager, Fisher \& Paykel and Xenios. P. Pickkers reports receiving travel reimbursements and consulting fees from AM-Pharma, Baxter, Adrenomed and EBI. J. Roberts has received 
grant funding from, or has consulted for, MSD, Cardeas Pharma, Accelerate Diagnostics, Pfizer, Astellas, Bayer and Biomerieux. A. Reintam-Blaser received consulting and speaker fees from Fresenius Kabi and Nestlé and a research grant (to University of Tartu, Estonia) from Fresenius Kabi. No potential conflict of interest was reported for other authors.

\section{Ethical approval}

An approval by an ethics committee was not applicable.

\section{Publisher's Note}

Springer Nature remains neutral with regard to jurisdictional claims in published maps and institutional affiliations.

Received: 17 January 2019 Accepted: 5 March 2019 Published online: 19 March 2019

\section{References}

1. Batsis JA, Villareal DT (2018) Sarcopenic obesity in older adults: aetiology, epidemiology and treatment strategies. Nat Rev Endocrinol 14:513-537

2. Piche ME, Poirier P, Lemieux I, Despres JP (2018) Overview of epidemiology and contribution of obesity and body fat distribution to cardiovascular disease: an update. Prog Cardiovasc Dis 61:103-113

3. Neeland IJ, Poirier P, Despres JP (2018) Cardiovascular and metabolic heterogeneity of obesity: clinical challenges and implications for management. Circulation 137:1391-1406

4. Sakr Y, Alhussami I, Nanchal R, Wunderink RG, Pellis T, Wittebole X, MartinLoeches I, Francois B, Leone M, Vincent $\mathrm{JL}$ (2015) Being overweight is associated with greater survival in ICU patients: results from the intensive care over nations audit. Crit Care Med 43:2623-2632

5. De Jong A, Verzilli D, Sebbane M, Monnin M, Belafia F, Cisse M, Conseil M, Carr J, Jung B, Chanques G, Molinari N, Jaber S (2018) Medical versus surgical ICU obese patient outcome: a propensity-matched analysis to resolve clinical trial controversies. Crit Care Med 46:e294-e301

6. Rosvall BR, Forgie K, MacLeod JB, Yip AM, Aguiar C, Lutchmedial S, Brown C, Forgie R, Legare JF, Hassan A (2017) Impact of obesity on intensive care unit resource utilization after cardiac operations. Ann Thorac Surg 104:2009-2015

7. Heymsfield SB, Wadden TA (2017) Mechanisms, pathophysiology, and management of obesity. N Engl J Med 376:254-266

8. Sharma A, Lavie CJ, Borer JS, Vallakati A, Goel S, Lopez-Jimenez F, ArbabZadeh A, Mukherjee D, Lazar JM (2015) Meta-analysis of the relation of body mass index to all-cause and cardiovascular mortality and hospitalization in patients with chronic heart failure. Am J Cardiol 115:1428-1434

9. Romero-Corral A, Montori VM, Somers VK, Korinek J, Thomas RJ, Allison TG, Mookadam F, Lopez-Jimenez F (2006) Association of bodyweight with total mortality and with cardiovascular events in coronary artery disease: a systematic review of cohort studies. Lancet 368:666-678

10. Naderi N, Kleine CE, Park C, Hsiung JT, Soohoo M, Tantisattamo E, Streja E, Kalantar-Zadeh K, Moradi H (2018) Obesity paradox in advanced kidney disease: from bedside to the bench. Prog Cardiovasc Dis 61:168-181

11. Nie W, Zhang Y, Jee SH, Jung KJ, Li B, Xiu Q (2014) Obesity survival paradox in pneumonia: a meta-analysis. BMC Med 12:61

12. Pepper DJ, Sun J, Welsh J, Cui X, Suffredini AF, Eichacker PQ (2016) Increased body mass index and adjusted mortality in ICU patients with sepsis or septic shock: a systematic review and meta-analysis. Crit Care 20:181

13. Ni YN, Luo J, Yu H, Wang YW, Hu YH, Liu D, Liang BM, Liang ZA (2017) Can body mass index predict clinical outcomes for patients with acute lung injury/acute respiratory distress syndrome? A meta-analysis. Crit Care 21:36

14. Hogue CW, Stearns JD, Colantuoni E, Robinson KA, Stierer T, Mitter N, Pronovost PJ, Needham DM (2009) The impact of obesity on outcomes after critical illness: a meta-analysis. Intensive Care Med 35:1152-1170

15. Wacharasint P, Boyd JH, Russell JA, Walley KR (2013) One size does not fit all in severe infection: obesity alters outcome, susceptibility, treatment, and inflammatory response. Crit Care 17:R122

16. Marques MB, Langouche L (2013) Endocrine, metabolic, and morphologic alterations of adipose tissue during critical illness. Crit Care Med 41:317-325
17. Alipoor E, Mohammad Hosseinzadeh F, Hosseinzadeh-Attar MJ (2018) Adipokines in critical illness: a review of the evidence and knowledge gaps. Biomed Pharmacother 108:1739-1750

18. Fantuzzi G (2005) Adipose tissue, adipokines, and inflammation. J Allergy Clin Immunol 115:911-919 (quiz 920)

19. Stapleton RD, Dixon AE, Parsons PE, Ware LB, Suratt BT (2010) The association between $\mathrm{BMI}$ and plasma cytokine levels in patients with acute lung injury. Chest 138:568-577

20. Murch O, Collin M, Hinds CJ, Thiemermann C (2007) Lipoproteins in inflammation and sepsis. I. Basic science. Intensive Care Med 33:13-24

21. Pepin JL, Timsit JF, Tamisier R, Borel JC, Levy P, Jaber S (2016) Prevention and care of respiratory failure in obese patients. Lancet Respir Med 4:407-418

22. De Jong A, Chanques G, Jaber S (2017) Mechanical ventilation in obese ICU patients: from intubation to extubation. Crit Care 21:63

23. Bazurro S, Ball L, Pelosi P (2018) Perioperative management of obese patient. Curr Opin Crit Care 24:560-567

24. Mullen JT, Moorman DW, Davenport DL (2009) The obesity paradox: body mass index and outcomes in patients undergoing nonbariatric general surgery. Ann Surg 250:166-172

25. Zhi G, Xin W, Ying W, Guohong X, Shuying L (2016) "Obesity paradox" in acute respiratory distress syndrome: a systematic review and meta-analysis. PLoS One 11:e0163677

26. Ball L, Serpa Neto A, Pelosi P (2017) Obesity and survival in critically ill patients with acute respiratory distress syndrome: a paradox within the paradox. Crit Care 21:114

27. De Jong A, Molinari N, Pouzeratte Y, Verzilli D, Chanques G, Jung B, Futier E, Perrigault PF, Colson P, Capdevila X, Jaber S (2015) Difficult intubation in obese patients: incidence, risk factors, and complications in the operating theatre and in intensive care units. Br J Anaesth 114:297-306

28. Delay JM, Sebbane M, Jung B, Nocca D, Verzilli D, Pouzeratte Y, Kamel ME, Fabre JM, Eledjam JJ, Jaber S (2008) The effectiveness of noninvasive positive pressure ventilation to enhance preoxygenation in morbidly obese patients: a randomized controlled study. Anesth Analg 107:1707-1713

29. Jaber S, Monnin M, Girard M, Conseil M, Cisse M, Carr J, Mahul M, Delay JM, Belafia F, Chanques G, Molinari N, De Jong A (2016) Apnoeic oxygenation via high-flow nasal cannula oxygen combined with non-invasive ventilation preoxygenation for intubation in hypoxaemic patients in the intensive care unit: the single-centre, blinded, randomised controlled OPTINIV trial. Intensive Care Med 42:1877-1887

30. Pelosi P, Croci M, Ravagnan I, Cerisara M, Vicardi P, Lissoni A, Gattinoni L (1997) Respiratory system mechanics in sedated, paralyzed, morbidly obese patients. J Appl Physiol 82:811-818

31. Pirrone M, Fisher D, Chipman D, Imber DA, Corona J, Mietto C, Kacmarek RM, Berra L (2016) Recruitment maneuvers and positive end-expiratory pressure titration in morbidly obese ICU patients. Crit Care Med 44:300-307

32. Pereira SM, Tucci MR, Morais CCA, Simoes CM, Tonelotto BFF, Pompeo MS, Kay FU, Pelosi P, Vieira JE, Amato MBP (2018) Individual positive end-expiratory pressure settings optimize intraoperative mechanical ventilation and reduce postoperative atelectasis. Anesthesiology 129:1070-1081

33. Futier E, Constantin JM, Pelosi P, Chanques G, Massone A, Petit A, Kwiatkowski F, Bazin JE, Jaber S (2011) Noninvasive ventilation and alveolar recruitment maneuver improve respiratory function during and after intubation of morbidly obese patients: a randomized controlled study. Anesthesiology 114:1354-1363

34. Ball L, Hemmes SNT, Serpa Neto A, Bluth T, Canet J, Hiesmayr M, HolImann MW, Mills GH, Vidal Melo MF, Putensen C, Schmid W, Severgnini P, Wrigge H, Gama de Abreu M, Schultz MJ, Pelosi P (2018) Intraoperative ventilation settings and their associations with postoperative pulmonary complications in obese patients. Br J Anaesth 121:899-908

35. Jaber S, Bellani G, Blanch L, Demoule A, Esteban A, Gattinoni L, Guérin C, Hill N, Laffey JG, Maggiore SM, Mancebo J, Mayo PH, Mosier JM, Navalesi P, Quintel M, Vincent JL, Marini JJ (2017) The intensive care medicine research agenda for airways, invasive and noninvasive mechanical ventilation. Intensive Care Med 43:1352-1365

36. Bime C, Fiero M, Lu Z, Oren E, Berry CE, Parthasarathy S, Garcia JGN (2017) High positive end-expiratory pressure is associated with improved survival in obese patients with acute respiratory distress syndrome. Am J Med 130:207-213 
37. De Jong A, Cossic J, Verzilli D, Monet C, Carr J, Conseil M, Monnin M, Cisse M, Belafia F, Molinari N, Chanques G, Jaber S (2018) Impact of the driving pressure on mortality in obese and non-obese ARDS patients: a retrospective study of 362 cases. Intensive Care Med 44:1106-1114

38. Fumagalli J, Berra L, Zhang C, Pirrone M, Santiago RRS, Gomes S, Magni F, Dos Santos GAB, Bennett D, Torsani V, Fisher D, Morais C, Amato MBP, Kacmarek RM (2017) Transpulmonary pressure describes lung morphology during decremental positive end-expiratory pressure trials in obesity. Crit Care Med 45:1374-1381

39. De Jong A, Molinari N, Sebbane M, Prades A, Futier E, Jung B, Chanques G, Jaber S (2013) Feasibility and effectiveness of prone position in morbidly obese patients with ARDS: a case-control clinical study. Chest 143:1554-1561

40. Kon ZN, Dahi S, Evans CF, Byrnes KA, Bittle GJ, Wehman B, Rector RP, McCormick BM, Herr DL, Sanchez PG, Pham SM, Griffith BP (2015) Class III obesity is not a contraindication to venovenous extracorporeal membrane oxygenation support. Ann Thorac Surg 100:1855-1860

41. Corley A, Bull T, Spooner AJ, Barnett AG, Fraser JF (2015) Direct extubation onto high-flow nasal cannulae post-cardiac surgery versus standard treatment in patients with a $\mathrm{BMI} \geq 30$ : a randomised controlled trial. Intensive Care Med 41:887-894

42. Carrillo A, Ferrer M, Gonzalez-Diaz G, Lopez-Martinez A, Llamas N, Alcazar M, Capilla L, Torres A (2012) Noninvasive ventilation in acute hypercapnic respiratory failure caused by obesity hypoventilation syndrome and chronic obstructive pulmonary disease. Am J Respir Crit Care Med 186:1279-1285

43. Stephan F, Berard L, Rezaiguia-Delclaux S, Amaru P (2017) High-flow nasal cannula therapy versus intermittent noninvasive ventilation in obese subjects after cardiothoracic surgery. Respir Care 62:1193-1202

44. Bur A, Hirschl MM, Herkner H, Oschatz E, Kofler J, Woisetschlager C, Laggner AN (2000) Accuracy of oscillometric blood pressure measurement according to the relation between cuff size and upper-arm circumference in critically ill patients. Crit Care Med 28:371-376

45. Tejedor A, Rivas E, Rios J, Arismendi E, Martinez-Palli G, Delgado S, Balust J (2015) Accuracy of Vigileo/Flotrac monitoring system in morbidly obese patients. J Crit Care 30:562-566

46. Nelson J, Billeter AT, Seifert B, Neuhaus V, Trentz O, Hofer CK, Turina M (2012) Obese trauma patients are at increased risk of early hypovolemic shock: a retrospective cohort analysis of 1,084 severely injured patients. Crit Care 16:R77

47. Adams C, Tucker C, Allen B, McRae A, Balazh J, Horst S, Johnson D, Ferreira J (2017) Disparities in hemodynamic resuscitation of the obese critically ill septic shock patient. J Crit Care 37:219-223

48. Winfield RD, Delano MJ, Dixon DJ, Schierding WS, Cendan JC, Lottenberg L, Lopez MC, Baker HV, Cobb JP, Moldawer LL, Maier RV, Cuschieri J (2010) Differences in outcome between obese and nonobese patients following severe blunt trauma are not consistent with an early inflammatory genomic response. Crit Care Med 38:51-58

49. Taylor SP, Karvetski CH, Templin MA, Heffner AC, Taylor BT (2018) Initial fluid resuscitation following adjusted body weight dosing is associated with improved mortality in obese patients with suspected septic shock. J Crit Care 43:7-12

50. Radosevich JJ, Patanwala AE, Erstad BL (2016) Norepinephrine dosing in obese and nonobese patients with septic shock. Am J Crit Care 25:27-32

51. Lu JL, Molnar MZ, Naseer A, Mikkelsen MK, Kalantar-Zadeh K, Kovesdy CP (2015) Association of age and BMI with kidney function and mortality: a cohort study. Lancet Diabetes Endocrinol 3:704-714

52. Kovesdy CP, Furth SL, Zoccali C (2017) Obesity and kidney disease: hidden consequences of the epidemic. Kidney Dis (Basel) 3:33-41

53. Druml W, Metnitz B, Schaden E, Bauer P, Metnitz PG (2010) Impact of body mass on incidence and prognosis of acute kidney injury requiring renal replacement therapy. Intensive Care Med 36:1221-1228

54. Danziger J, Chen KP, Lee J, Feng M, Mark RG, Celi LA, Mukamal KJ (2016) Obesity, acute kidney injury, and mortality in critical illness. Crit Care Med 44:328-334

55. McGuire TR, Brusnahan SK, Bilek LD, Jackson JD, Kessinger MA, Berger AM, Garvin KL, O'Kane BJ, Tuljapurkar SR, Sharp JG (2011) Inflammation associated with obesity: relationship with blood and bone marrow endothelial cells. Obesity (Silver Spring) 19:2130-2136

56. Serrano PE, Khuder SA, Fath JJ (2010) Obesity as a risk factor for nosocomial infections in trauma patients. J Am Coll Surg 211:61-67
57. Sheridan PA, Paich HA, Handy J, Karlsson EA, Hudgens MG, Sammon AB, Holland LA, Weir S, Noah TL, Beck MA (2012) Obesity is associated with impaired immune response to influenza vaccination in humans. Int J Obes (Lond) 36:1072-1077

58. Fezeu L, Julia C, Henegar A, Bitu J, Hu FB, Grobbee DE, Kengne AP, Hercberg S, Czernichow S (2011) Obesity is associated with higher risk of intensive care unit admission and death in influenza A (H1N1) patients: a systematic review and meta-analysis. Obes Rev 12:653-659

59. Green WD, Beck MA (2017) Obesity altered T cell metabolism and the response to infection. Curr Opin Immunol 46:1-7

60. Cascio V, Hon M, Haramati LB, Gour A, Spiegler P, Bhalla S, Katz DS (2018) Imaging of suspected pulmonary embolism and deep venous thrombosis in obese patients. Br J Radiol 91:20170956

61. Venclauskas L, Maleckas A, Arcelus JI (2018) European guidelines on perioperative venous thromboembolism prophylaxis: surgery in the obese patient. Eur J Anaesthesiol 35:147-153

62. Ji Y, Cheng B, Xu Z, Ye H, Lu W, Luo X, Fu S, Fang X (2018) Impact of sarcopenic obesity on 30-day mortality in critically ill patients with intraabdominal sepsis. J Crit Care 46:50-54

63. McClave SA, Taylor BE, Martindale RG, Warren MM, Johnson DR, Braunschweig C, McCarthy MS, Davanos E, Rice TW, Cresci GA, Gervasio JM, Sacks GS, Roberts PR, Compher C (2016) Guidelines for the provision and assessment of nutrition support therapy in the adult critically ill patient: society of critical care medicine (SCCM) and American Society for Parenteral and Enteral Nutrition (A.S.P.E.N.). JPEN J Parenter Enteral Nutr 40:159-211

64. Singer P, Blaser AR, Berger MM, Alhazzani W, Calder PC, Casaer MP, Hiesmayr M, Mayer K, Montejo JC, Pichard C, Preiser JC, van Zanten ARH, Oczkowski S, Szczeklik W, Bischoff SC (2019) ESPEN guideline on clinical nutrition in the intensive care unit. Clin Nutr 38:48-79

65. Reintam Blaser A, Starkopf J, Alhazzani W, Berger MM, Casaer MP, Deane AM, Fruhwald S, Hiesmayr M, Ichai C, Jakob SM, Loudet Cl, Malbrain ML, Montejo Gonzalez JC, Paugam-Burtz C, Poeze M, Preiser JC, Singer P, van Zanten AR, De Waele J, Wendon J, Wernerman J, Whitehouse T, Wilmer A, Oudemans-van Straaten HM (2017) Early enteral nutrition in critically ill patients: ESICM clinical practice guidelines. Intensive Care Med 43:380-398

66. Goossens C, Vander Perre S, Van den Berghe G, Langouche L (2017) Proliferation and differentiation of adipose tissue in prolonged lean and obese critically ill patients. Intensive Care Med Exp 5:16

67. Dickerson RN, Medling TL, Smith AC, Maish GO 3rd, Croce MA, Minard G, Brown RO (2013) Hypocaloric, high-protein nutrition therapy in older vs younger critically ill patients with obesity. JPEN J Parenter Enteral Nutr 37:342-351

68. Arabi YM, Casaer MP, Chapman M, Heyland DK, Ichai C, Marik PE, Martindale RG, McClave SA, Preiser JC, Reignier J, Rice TW, Van den Berghe G, van Zanten ARH, Weijs PJM (2017) The intensive care medicine research agenda in nutrition and metabolism. Intensive Care Med 43:1239-1256

69. Cho S-J, Yoon I-S, Kim DD (2013) Obesity-relaed physiological changes and their pharmacokinetic consequences. J Pharmaceut Investig 43:161-169

70. Pai MP (2012) Drug dosing based on weight and body surface area: mathematical assumptions and limitations in obese adults. Pharmacotherapy 32:856-868

71. Roberts JA, Abdul-Aziz MH, Lipman J, Mouton JW, Vinks AA, Felton TW, Hope WW, Farkas A, Neely MN, Schentag JJ, Drusano G, Frey OR, Theuretzbacher U, Kuti JL (2014) Individualised antibiotic dosing for patients who are critically ill: challenges and potential solutions. Lancet Infect Dis 14:498-509

72. Parienti JJ, Thirion M, Megarbane B, Souweine B, Ouchikhe A, Polito A Forel JM, Marque S, Misset B, Airapetian N, Daurel C, Mira JP, Ramakers M, du Cheyron D, Le Coutour X, Daubin C, Charbonneau P (2008) Femoral vs jugular venous catheterization and risk of nosocomial events in adults requiring acute renal replacement therapy: a randomized controlled trial. JAMA 299:2413-2422

73. Shea JM, Gagnon M (2015) Working with patients living with obesity in the intensive care unit: a study of nurses' experiences. ANS Adv Nurs Sci 38:E17-E37

74. Hales C, de Vries K, Coombs M (2016) Managing social awkwardness when caring for morbidly obese patients in intensive care: a focused ethnography. Int J Nurs Stud 58:82-89 